Bài báo khoa hoc

\title{
Đặc điểm thành phần và phân bố hạt vi nhựa trong môi trường trầm tích tầng mặt khu vực vịnh Tiên Yên
}

\author{
Trương Hưu Dực ${ }^{1,2}$, Lưu Việt Dũng ${ }^{1,2 *}$ Nguyễn Đình Thái ${ }^{2}$, Lê Văn Dũng ${ }^{1,2}$, Lê Thị \\ Khánh Linh ${ }^{1,2}$, Trần Đăng Quy ${ }^{1,2}$, Nguyễn Tài Tuệ ${ }^{1,2}$ \\ ${ }^{1}$ Phòng thí nghiệm trọng điểm Địa môi trường và Úng phó biến đổi khí hậu, Trường Đại \\ học Khoa học Tự nhiên, Đại học Quốc gia Hà Nội; trhduc98@gmail.com; \\ dungluuviet@gmail.com; levandung.qltnmtkhtn@gmail.com; \\ lethikhanhlinh_t61@hus.edu.vn; quytrandang@gmail.com; tuenguyentai@gmail.com \\ 2 Khoa Địa chất, Trường Đại học Khoa học Tự nhiên, Đại học Quốc gia Hà Nội; \\ nguyendinhthai@gmail.com \\ * Tác giả liên hệ: dungluuviet@gmail.com; Tel.: +84-904729009
}

Ban Biên tập nhận bài: 2/10/2020; Ngày phản biện xong: 26/10/2020; Ngày đăng bài: $25 / 11 / 2020$

Tóm tắt: Vấn đề ô nhiễm rác thải nhựa trên biển và đại dương, đặc biệt là các hạt vi nhựa đã gây tác động bất lợi cho môi trường và các hệ sinh thái biển trong giai đoạn gần đây. Các nghiên cứu gần đây cho thấy Việt Nam là một trong những nước đứng đầu về thất thoát rác thải nhựa ra môi trường biển và đại dương nên các nghiên cứu về hạt vi nhựa trong môi trường là rất cần thiết. Trong phạm vi của nghiên cứu này, đặc điểm phân bố về số lượng và thành phần hóa học của hạt vi nhựa trong môi trường trầm tích tầng mặt khu vực vịnh Tiên Yên đã được đánh giá cụ thể. Kết quả nghiên cứu cho thấy trầm tích tầng mặt khu vực vịnh Tiên Yên bị nhiễm bẩn từ 236-1324 hạt vi nhựa/kg, với giá trị trung bình $664 \pm 68$ hạt vi nhựa $/ \mathrm{kg}$. Số lượng các loại hạt vi nhựa trong môi trường trầm tích vịnh Tiên Yên bao gồm Microfragment $(8,54 \%)$, Microfoam (4,99\%), Microfiber $(84,9 \%)$ và Microfilm $(1,57 \%)$. Thành phần hóa học của vi nhựa chủ yếu là các loại nhựa phổ biến như $\mathrm{PE}, \mathrm{PP}$, PA, PVC, PS, PET. Hạt vi nhựa có xu hướng tập trung tại khu vực phía Bắc vịnh Tiên Yên có liên quan đến các hoạt động nhân sinh trong khu vực nghiên cứu. Mức độ nhiễm bẩn hạt vi nhựa trong môi trường trầm tích vịnh Tiên Yên hiện nay ở mức tương đối cao khi so sánh với các khu vực khác trên thế giới nên cần có giải pháp quản lý tài nguyên và môi trường phù hợp.

Từ khóa: Vi nhựa; Trầm tích tầng mặt; Vịnh Tiên Yên.

\section{Mở đầu}

Các sản phẩm nhựa (plastics) được sản xuất công nghiệp và sử dụng rộng rãi từ giai đoạn 1940 trở lại đây và có vai trò đặc biệt quan trọng với nhiều ngành kinh tế và đời sống của người dân trên thế giới [1]. Tuy vậy, việc gia tăng nhu cầu sử dụng các sản phẩm nhựa (ước tính lên đến 12 tỷ tấn vào năm 2025 [2]), rác thải nhựa ngày càng gây nhiều ảnh hưởng đến môi trường, đặc biệt là các hệ sinh thái biển và ven biển. Hàng năm đại dương nhận khoảng 4,8 đến 12,7 triệu tấn rác thải nhựa từ đất liền từ các hoạt động đánh bắt thủy hải sản, du lịch, đặc biệt là lượng rác thải sinh hoạt, công nghiệp ngày càng gia tăng [3]. Phần lớn các thành phần nhựa đều khó phân hủy sinh học, chúng chỉ bị vỡ ra thành các mảnh bé hơn bởi các tác 
nhân vật lý như tia UV, sóng hay va đập vào rạn san hô, trầm tích. Các mảnh nhựa có kích thước $<5 \mathrm{~mm}$ được gọi là microplastics hay hạt vi nhựa [4-5]. Bên cạnh việc lượng lớn rác thải nhựa thải ra môi trường gây suy giảm chất lượng môi trường, hạt vi nhựa còn là tác nhân gây ảnh hưởng tiêu cực đến hệ sinh thái [6]. Các hạt vi nhựa được phân loại thành hạt vi nhựa sơ cấp và hạt vi nhựa thứ cấp [7]. Hạt vi nhựa sơ cấp được sản xuất phục vụ cho công nghiệp nhựa với hình dạng và kích thước cụ thể và thường có dạng hình cầu. Hạt vi nhựa thứ cấp là sản phẩm của quá trình phân hủy các loại rác thải nhựa trong môi trường [8]. Hạt vi nhựa rất phổ biến trong môi trường biển và đại dương, chúng có thể trôi nổi trên bề mặt đại dương hay lắng đọng trong trầm tích ở khắp các đại dương trên thế giới. Các nghiên cứu gần đây đã ghi nhận sự xuất hiện của hạt vi nhựa trong cơ thể của nhiều loài cá, rùa hay chim biển [9], trong các loài động vật phù du [10] và trong ruột của các loài sinh vật hai mảnh vỏ [11]. Hạt vi nhựa tích lũy trong cơ thể sinh vật có thể làm giàu thông qua chuỗi thức ăn gây ảnh hưởng đến nhiều loài khác, kể cả con người. Hơn thế nữa, hạt vi nhựa có thể hấp phụ các chất ô nhiễm hữu cơ, kim loại nặng, PCBs gây tác động có hại lên nhiều loại động vật và hệ sinh thái [12-14].

Việt Nam được đánh giá là nước đứng thứ 4 thế giới về lượng rác thải nhựa thải ra môi trường biển với 18000 tấn một năm, đứng sau Trung Quốc, Philipines và Indonesia [3]. Các nghiên cứu gần đây về phân bố hạt vi nhựa tại Việt Nam cho thấy môi trường nước các kênh rạch gần các nhà máy trên sông Sài Gòn bị nhiễm bẩn các loại hạt vi nhựa có nguồn gốc từ dệt may [15]. Mức độ nhiễm bẩn vi nhựa trong cát bãi biển tại khu vực thành phố Vũng Tàu và huyện Gò Công, tỉnh Tiền Giang cũng ở mức khá cao, với thành phần chủ yếu là các loại nhựa Polyethylene, Polypropylene, Polystyren [16]. Tuy nhiên, các nghiên cứu về nhiễm bẩn hạt vi nhựa trong trầm tích đáy biển còn khá hạn chế, đặc biệt tại các vũng vịnh ven biển. Vũng vịnh là môi trường chuyển tiếp quan trọng giữa đất liền và biển, đồng thời là nơi tích lũy các loại rác thải nhựa từ đất liền trước khi được động lực sóng, thủy triều và các dòng hải lưu mang chúng ra các đại dương. Vịnh Tiên Yên nằm tại phía Đông Bắc nước ta có diện tích tương đối lớn rộng khoảng $9 \mathrm{~km}$, dài khoảng $57 \mathrm{~km}$ [17]. Phía Tây vịnh là địa phận của các huyện Tiên Yên, Đầm Hà, Hải Hà, Móng Cái, phía Đông vịnh bao bọc bởi dãy đảo chắn Cái Bầu-Vĩnh Thực [18]. Vịnh Tiên Yên là khu vực có vị trí quan trọng trong quá trình phát triển khu kinh tế Vân Đồn, đồng thời cũng có nguy cơ tích lũy rác thải nhựa và các chất ô nhiễm trong tương lai. Do đó, nghiên cứu này được thực hiện nhằm đánh giá mức độ nhiễm bẩn và sự phân bố của hạt vi nhựa trong trầm tích tầng mặt vịnh Tiên Yên. Các đặc điểm về số lượng, phân loại, thành phần hóa học và sự phân bố không gian của các loại hạt vi nhựa trong trầm tích tầng mặt khu vực vịnh Tiên Yên sẽ được đánh giá cụ thể trong nghiên cứu. Kết quả nghiên cứu sẽ cung cấp các thông tin ban đầu về mức độ nhiễm bẩn hạt vi nhựa trong môi trường trầm tích vịnh Tiên Yên, là cơ sở đề xuất các giải pháp quản lý giảm thiểu ô nhiễm rác thải nhựa trong các giai đoạn tiếp theo.

\section{Phương pháp nghiên cứu}

\subsection{Khu vục nghiên cúu}

Khu vực nghiên cứu được giới hạn từ cửa sông Tiên Yên, huyện Tiên Yên đến địa phận thị trấn Quảng Hà, huyện Hải Hà, phía Tây bởi nhóm đảo chắn Cái Bầu-Vĩnh Thực (Hình 1). Vịnh Tiên Yên là một vịnh kín và là môi trường chuyển tiếp của nhiều sông ra vịnh Bắc Bộ như sông Tiên Yên, Ba Chẽ, Đầm Hà, Hà Cối [19]. Vùng bờ khu vực vịnh Tiên Yên phát triển hệ thống rừng ngập mặn (gần 5000 ha) và bãi triều thấp (13000 ha) với mức độ đa dạng sinh học cao. Hệ thống rừng ngập mặn trong khu vực vịnh Tiên Yên là một trong những khu rừng ngập mặn nguyên sinh còn sót lại ở miền Bắc Việt Nam, có vai trò quan trọng đối với các hệ sinh thái biển tại khu vực nghiên cứu [20]. Trong quá trình phát triển khu kinh tế Vân Đồn, vịnh Tiên Yên có nguy cơ cao trở thành nơi tích lũy các loại chất ô nhiễm và rác thải, ảnh hưởng đến tài nguyên và các hệ sinh thái đất ngập nước trong khu vực. 


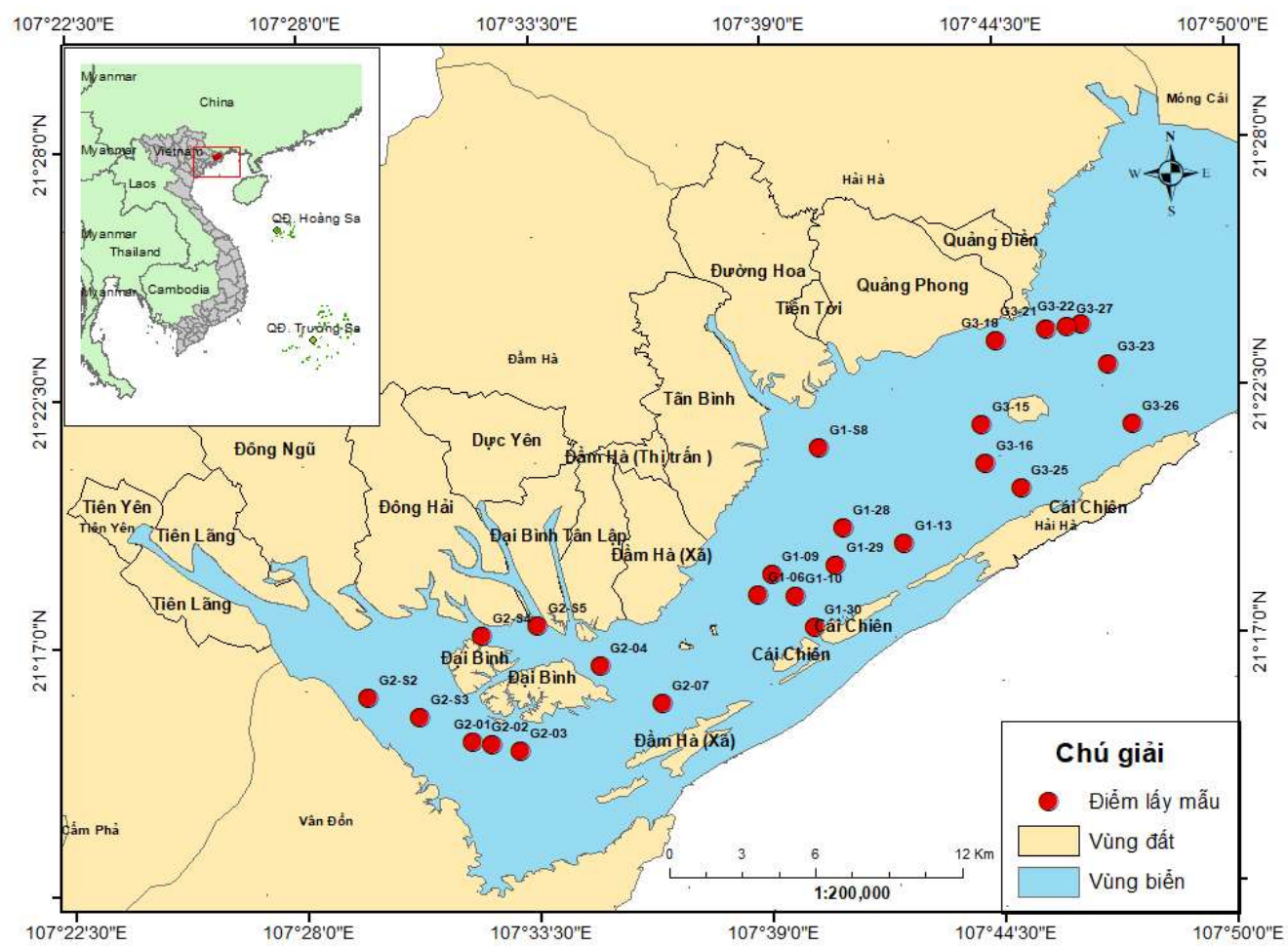

Hình 1. Vị trí lấy mẫu trầm tích khu vực vịnh Tiên Yên, tỉnh Quảng Ninh.

\subsection{Khảo sát thục địa và lấy mẫu}

Quá trình khảo sát thực địa được tiến hành vào tháng 9/2019 với 26 mẫu trầm tích tầng mặt được thu thập tại khu vực vịnh Tiên Yên (Hình 1). Mẫu được lấy bằng gàu lấy mẫu trầm tích chuyên dụng với bề dày trầm tích tầng mặt khoảng $5 \mathrm{~cm}$. Mẫu trầm tích sau khi lấy được đựng trong túi $\mathrm{PE}$ chuyên dụng (GL Science, Japan), lưu trữ trong thùng giữ nhiệt và bảo quản mát cho đến khi được chuyển về phòng thí nghiệm trước khi tiến hành các thí nghiệm tiếp theo. Khu vực lấy mẫu được phân chia tương ứng theo ký hiệu G1, G2, G3 đại diện cho khu vực trung tâm vịnh Tiên Yên, khu vực phía Nam vịnh Tiên Yên và khu vực phía Bắc vịnh Tiên Yên.

\subsection{Phuơng pháp xác định số luọng và phân loại hạt vi nhựa trong môi truờng trầm tích tầng mặt}

Phương pháp xác định số lượng hạt vi nhựa trong môi trường trầm tích tầng mặt áp dụng theo quy trình của NOAA đã được điều chỉnh cho phù hợp với điều kiện Việt Nam [21]. Khoảng $200 \mathrm{~g}$ mẫu trầm tích tầng mặt vịnh Tiên Yên được sấy khô ở nhiệt độ ở $60^{\circ} \mathrm{C}$ đến khối lượng không đổi trong 24 đển 48 giờ. Sau khi sấy khô, mẫu được chia thành các phần khoảng $50-70 \mathrm{~g}$ trầm tích khô đựng ở cốc thủy tinh và thêm từ từ $30-50 \mathrm{ml}$ dung dịch Perodioxit $10 \%$. Khi phản ứng kết thúc, mẫu được mang đi rây ướt với rây $0,3 \mathrm{~mm}$ để loại bỏ các hạt có kích thước nhỏ, phần còn lại trên rây được rửa vào cốc thủy tinh và sấy khô ở nhiệt độ $60^{\circ} \mathrm{C}$ trong $24 \mathrm{~h}$. Mẫu trong cốc thủy tinh sau khi sấy được xử lý loại bỏ thành phần vật chất hữu cơ bằng $30-50 \mathrm{ml}$ dung dịch Hydro Peroxide $30 \%$ với chất xúc tác là dung dịch FeSO4 0,5M [19]. Mẫu trầm tích gần bờ là môi trường sống của nhiều loài sinh vật bám đáy nên có thành phần carbonat từ vụn vỏ sinh vật khá lớn. Đối với các mẫu có nhiều thành phần vụn vỏ sinh vật, khoảng $10-20 \mathrm{ml}$ dung dịch $\mathrm{HCl} 1 \mathrm{M}$ được thêm vào để loại bỏ thành phần carbonat trong vòng $12 \mathrm{~h}$ (hoặc đến khi dừng xuất hiện bọt khí). Mẫu sau phản ứng được sấy khô đến khi khối lượng không đổi trước khi tiến hành ly tâm tách các hạt vi nhựa ra khỏi trầm tích. Mẫu trầm tích sau khi loại bỏ vật chất hữu cơ và carbonat được đựng trong các ống 
nhựa ly tâm $\mathrm{PE}$ và thêm đầy bằng dung dịch $\mathrm{ZnCl} 21,6 \mathrm{~g} / \mathrm{l}$. Hỗn hợp này được ly tâm tốc độ cao (3000 RCF trong 5 phút) 3 lần nhằm tách các hạt vi nhựa có tỉ trọng bé nổi phía trên. Phần hạt vi nhựa nổi lên trên được lọc qua giấy lọc kẻ ô Milipore với đường kính $47 \mathrm{~mm}$, kích thước lỗ lọc $0,45 \mu \mathrm{m}$ với bộ lọc chân không Nagalene. Trong quá trình lọc, nước cất được thêm vào để đảm bảo không còn $\mathrm{ZnCl}_{2}$ tồn dư trên màng lọc. Màng lọc sau khi lọc được đựng trong các túi giấy nhôm, sấy khô ở $45^{\circ} \mathrm{C}$ đến khối lượng không đổi. Đặc điểm về số lượng hạt vi nhựa trong trầm tích được xác định bằng kính hiển vi soi nổi theo hướng dẫn của cơ quan khí quyển và đại dương Hoa Kỳ NOAA [4, 19]. Việc xác định và phân loại thành phần của các loại hạt vi nhựa có trong môi trường trầm tích sẽ được thực hiện theo hướng dẫn của NOAA [4].

\subsection{Phưong pháp xác định thành phần hóa học của các hạt vi nhựa}

Do khối lượng hạt vi nhựa thu được sau quá trình lọc khá nhỏ nên các mẫu hạt vi nhựa phân bố tại khu vực phía Bắc, Trung tâm và phía Nam vịnh Tiên Yên được gộp chung để xác định thành phần hóa học bằng phương pháp quang phổ hồng ngoại hấp phụ FTIR (Fouriertransform infrared spectroscopy). Đây là phương pháp phổ biến để xác định thành phần hóa học của hạt vi nhựa trong các nghiên cứu gần đây [26]. Hạt vi nhựa ở các mẫu thuộc vùng phía Bắc, Trung và Nam vịnh Tiên Yên được gom lại thành 3 mẫu có khối lượng khoảng 3$5 \mathrm{mg}$ để xác định thành phần hóa học. Các mẫu này được nghiền mịn với chất nền $\mathrm{KBr}$ bằng cối mã não và được nén chặt bằng máy nén trên đĩa kim loại trước khi tiến hành phân tích bằng hệ thống quang phổ hồng ngoại hấp phụ Jasco FTIR 4600. Quá trình phân tích được thực hiện tại Trường Đại học Khoa học Tự nhiên, Đại học Quốc gia Hà Nội. Phổ phân tích FTIR của mẫu hạt vi nhựa được so sánh và phân loại thành phần hóa học theo công bố của Gerrit Renner [22].

\subsection{Phưong pháp xủ lý số liệu}

Kết quả thu được trong quá trình phân tích hạt vi nhựa trong môi trường trầm tích sẽ được tính toán các giá trị trung bình bằng phần mềm SPSS 20.0, các biểu đồ được trình bày bằng phần mềm Sigmaplot 12.0. Để xác định sự khác biệt thống kê về phân bố các loại hạt vi nhựa trong môi trường trầm tích theo không gian, phương pháp phân tích phương sai (ANOVA) được thực hiện trên kết quả phân tích số lượng hạt vi nhựa. Trước khi tiến hành phân tích, tập mẫu được kiểm định phân phối chuẩn để đáp ứng điều kiện của phân tích phương sai. Trong trường hợp tập mẫu không đáp ứng phân phối chuẩn, phương pháp Kruskal-Wallis ANOVA được áp dụng để kiểm định khác biệt thống kê về số lượng hạt vi nhựa trong trầm tích. Sự khác biệt thống kê giữa các nhóm được ghi nhận khi giá trị $\mathrm{p}<0,05$.

\section{Kết quả và thảo luận}

\section{1. Đặc điểm phân bố của các loại hạt vi nhựa trong trầm tích tầng mặt vịnh Tiên Yên}

Đặc điểm thành phần số lượng hạt vi nhựa trong trầm tích tầng mặt vịnh Tiên Yên, tỉnh Quảng Ninh thể hiện trong Hình 2. Kết quả nghiên cứu cho thấy ở khu vực vịnh, số lượng hạt vi nhựa dao động từ 236-1324 hạt vi nhựa/kg với giá trị trung bình là $664 \pm 68$ hạt vi nhựa/kg. Ở các mẫu G1-29, G1-30, G1-S08, G2-03, G3-15, G3-25 là những điểm tập trung nhiều nhất với số lượng lớn hơn 1000 hạt vi nhựa/kg. Khu vực phía Bắc và Trung tâm vịnh Tiên Yên có xu hướng tập trung hạt vi nhựa cao hơn so với khu vực phía Nam của vịnh Tiên Yên (Hình 2,4). Mức độ nhiễm bẩn hạt vi nhựa trong môi trường trầm tích tầng mặt vịnh Tiên Yên nằm ở mức tương đối cao khi so sánh với khu vực tương tự ở Australia và một số vùng cửa sông ở Trung Quốc (Bảng 1). Các giá trị này cũng tương đương với một số điểm được đánh giá là ô nhiễm rác thải nhựa của Trung Quốc [23-24]. Hạt vi nhựa trong trầm tích vịnh Tiên Yên được phân loại với 4 loại chính là Microfiber, Microfoam, Microfragment, 
Microfilm và không có sự xuất hiện của một số nhóm hạt vi nhựa nguyên sinh khác. Sự khác biệt về thống kê về phân bố không gian trong khu vực nghiên cứu chỉ ghi nhận đối với hạt vi nhựa Microfragments và không xuất hiện đối với các nhóm hạt còn lại.

Microfiber chiếm 84,90\% thành phần số lượng hạt vi nhựa trong trầm tích tầng mặt vịnh Tiên Yên. Microfiber là loại vi nhựa có dạng sợi, mỏng và dài và rất dễ nhận biết dưới kính hiển vi bởi hình dạng sợi đặc trưng với nhiều màu, trắng, xanh lục, lam, đỏ, trong suốt... kích thước khá đa dạng từ $0,5-5 \mathrm{~mm}$. Microfiber dạng sợi trong suốt và dẻo xuất hiện rất nhiều trong khu vực vịnh Tiên Yên, chúng là sản phẩm phân hủy của các dây lưới đánh cá hay dây câu hoặc từ vải may mặc, sản phẩm vệ sinh. Các hạt Microfiber với nhiều màu sắc thường có nguồn gốc từ các sợi len hoặc các sợi vải tổng hợp cũng bắt gặp với số lượng hạn chế trong khu vực nghiên cứu. Đặc điểm phân bố của Microfiber trong trầm tích cho thấy các hạt này có xu hướng tập trung tương đối cao khu vực phía Bắc vịnh Tiên Yên (Kruskal-Wallis ANOVA, $p=0,173$ ) (Hình $6 b$ ). Đây là khu vực nơi tập trung các hoạt động nuôi ngao, cá lồng bè, đánh bắt thủy sản và hoạt động của các khu công nghiệp liên quan đến lĩnh vực dệt nhuộm và may mặc [19].

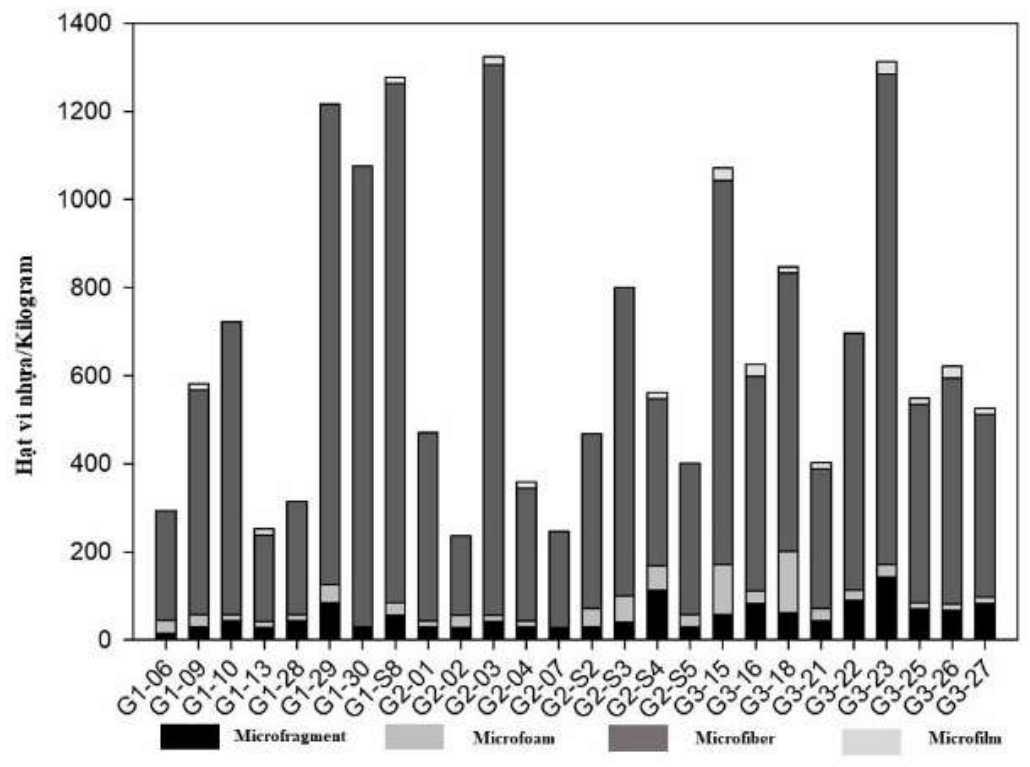

Hình 2. Số lượng và phân loại các loại hạt vi nhựa trong trầm tích khu vực.

Bảng 1. Mức độ nhiễm bẩn của vi nhựa tại vịnh Tiên Yên và các khu vực khác trên thế giới.

\begin{tabular}{lcc}
\hline \multicolumn{1}{c}{ Khu vụ̣c nghiên cứu } & Kích thước $(\mathbf{m m})$ & Hạt vi $\mathbf{n h u ̣ a} / \mathbf{k g}$ \\
\hline Vịnh Tiên Yên, tỉnh Quảng Ninh & $0,25-5$ & DĐ: $236-1324$ \\
& & TB: 664 \\
Bờ Đông Úc [23] & $0,2-5$ & DĐ: $83-350$ \\
& & \\
Hồng Kông [24] & $0.1-5$ & DĐ: $44-458$ \\
Cửa sông Trường Giang, & $<5$ & TB: 158 \\
Trung Quốc [25] & & DĐ: $20-340$ \\
Vịnh Sishili, Hoàng Hải, Trung & $<5$ & TB: 121 \\
Quốc [26] & & DĐ: $140-1873$ \\
\hline
\end{tabular}




\begin{tabular}{ccc}
\hline Khu vực nghiên cứu & Kích thước $(\mathbf{m m})$ & Hạt vi nhựa/kg \\
\hline Vịnh Sanggou, Trung Quốc [27] & $<5$ & DĐ: $699-2824$ \\
& & TB: 1674 \\
\hline
\end{tabular}

DĐ: Khoảng dao động; TB: Giá trị trung bình

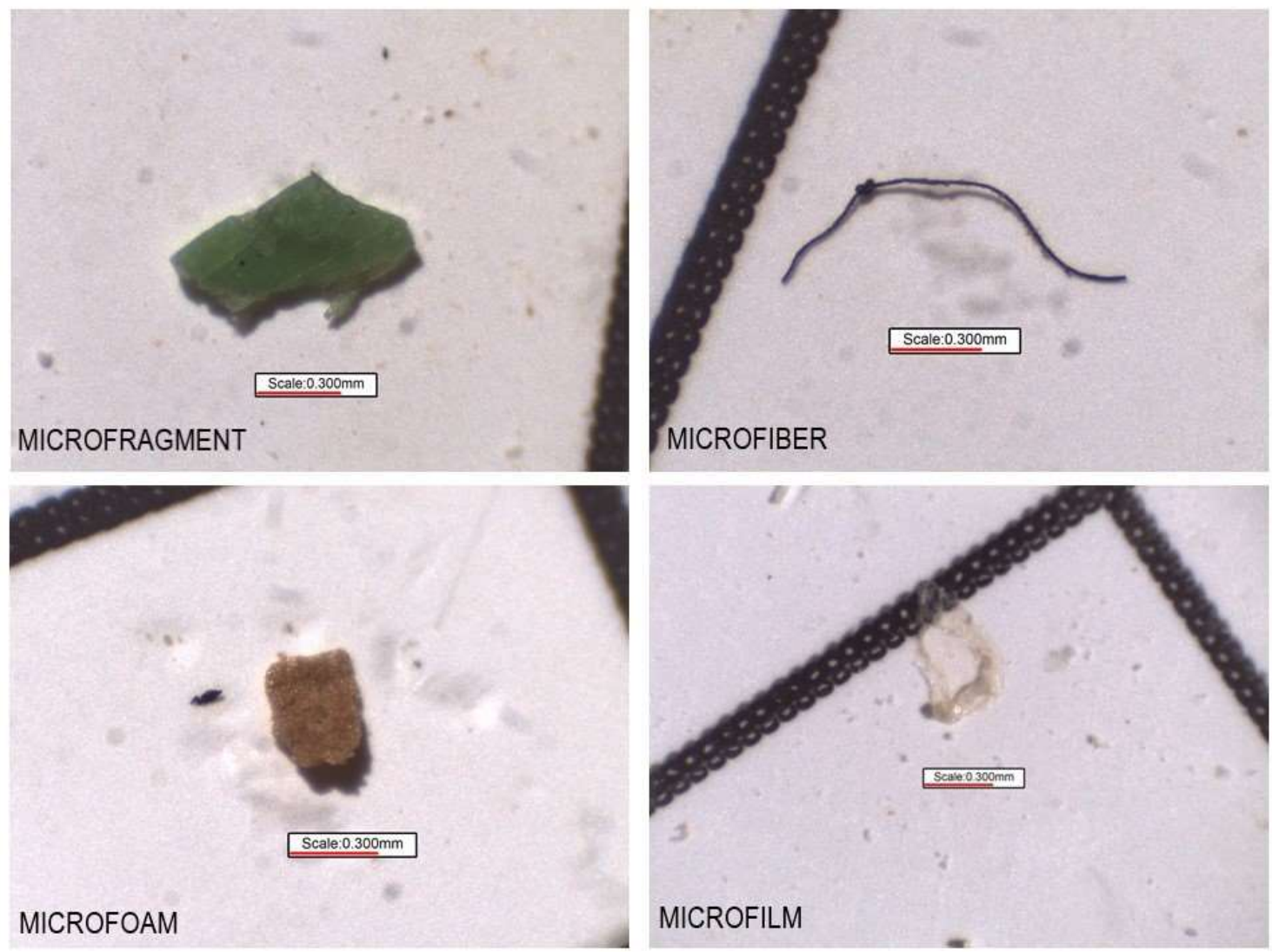

Hình 3. Hình thái của một số loại hạt vi nhựa trong trầm tích tầng mặt vịnh Tiên Yên.

Microfragment là loại hạt vi nhựa phổ biến thứ hai trong trầm tích vịnh Tiên Yên chiếm khoảng $8,54 \%$ thành phần số lượng. Microfragment có nhiều hình dạng, màu sắc và kích cỡ khác nhau. Tại khu vực nghiên cứu, các hạt Microfragment thường có màu xanh, vàng, trắng, xanh lam, với hình dạng chủ yếu là dạng mảnh vỡ. Kích thước của Microfragment khá đa dạng nhưng chủ yếu nằm trong khoảng từ $0,3 \mathrm{~mm}$ đến $2 \mathrm{~mm}$. Microfragment là sản phẩm phân rã từ các sản phẩm nhựa dùng một lần như chai nhựa, ly nhựa, ống nhựa và các sản phẩm nhựa gia dụng. Các loại nhựa dưới tác dụng của sóng, tia UV hay va đập sẽ vỡ ra thành các mảnh nhỏ. Tương tự như Microfiber, các hạt Microfragment tập trung chủ yếu tại khu vực phía Bắc của vịnh Tiên Yên (Kruskal-Wallis ANOVA, $p=0,006$ ) là khu vực tập trung nhiều hoạt động nhân sinh (Hình 6a).

Microfoam là loại hạt vi nhựa có kích thước tương đối lớn, cấu trúc xốp với hình dạng khá đa dạng thường có màu trắng xám hoặc vàng nâu. Mức độ xuất hiện của Microfoam trong trầm tích tương đối ít chiếm khoảng $4,99 \%$ thành phần số lượng hạt vi nhựa trong môi trường trầm tích tại khu vực nghiên cứu hình $6 \mathrm{c}$ (Kruskal-Wallis ANOVA, $\mathrm{p}=0,597)$. Microfoam thường có tỷ trọng nhẹ nên ít gặp hơn trong môi trường trầm tích so với các Microfiber và Microfragment.

Microfilm là các mảnh vi nhựa có dạng tấm mỏng thấu quang có thường liên quan đến túi nylon và bao bì nhựa. Microfilm chiếm $1,57 \%$ thành phần số lượng hạt vi nhựa trong trầm 
tích tầng mặt khu vực vịnh Tiên Yên. Microfilm trong trầm tích tại khu vực nghiên cứu thường trong suốt, có thể gặp màu xanh nhạt hoặc vàng. Kích thước của microfilm dao động từ $0,5-1 \mathrm{~mm}$ và ít gặp các mảnh có kích thước lớn hơn. Microfilm chủ yếu phân bố trong trầm tích tầng mặt tại phía Bắc vùng nghiên cứu và gần đảo Cái Chiên (Kruskal-Wallis ANOVA, $p=0,082$ ), nơi có hoạt động đánh bắt thủy sản nhộn nhịp (Hình $6 \mathrm{~d}$ ) [19]. Nhìn chung, Microfilm và Microfoam thường có tỷ trọng nhẹ nên có xu hướng ít lắng đọng trong môi trường trầm tích so với các loại hạt vi nhựa khác.

\subsection{Thành phần hóa học của các hạt vi nhựa trong trầm tích khu vục nghiên cúu}

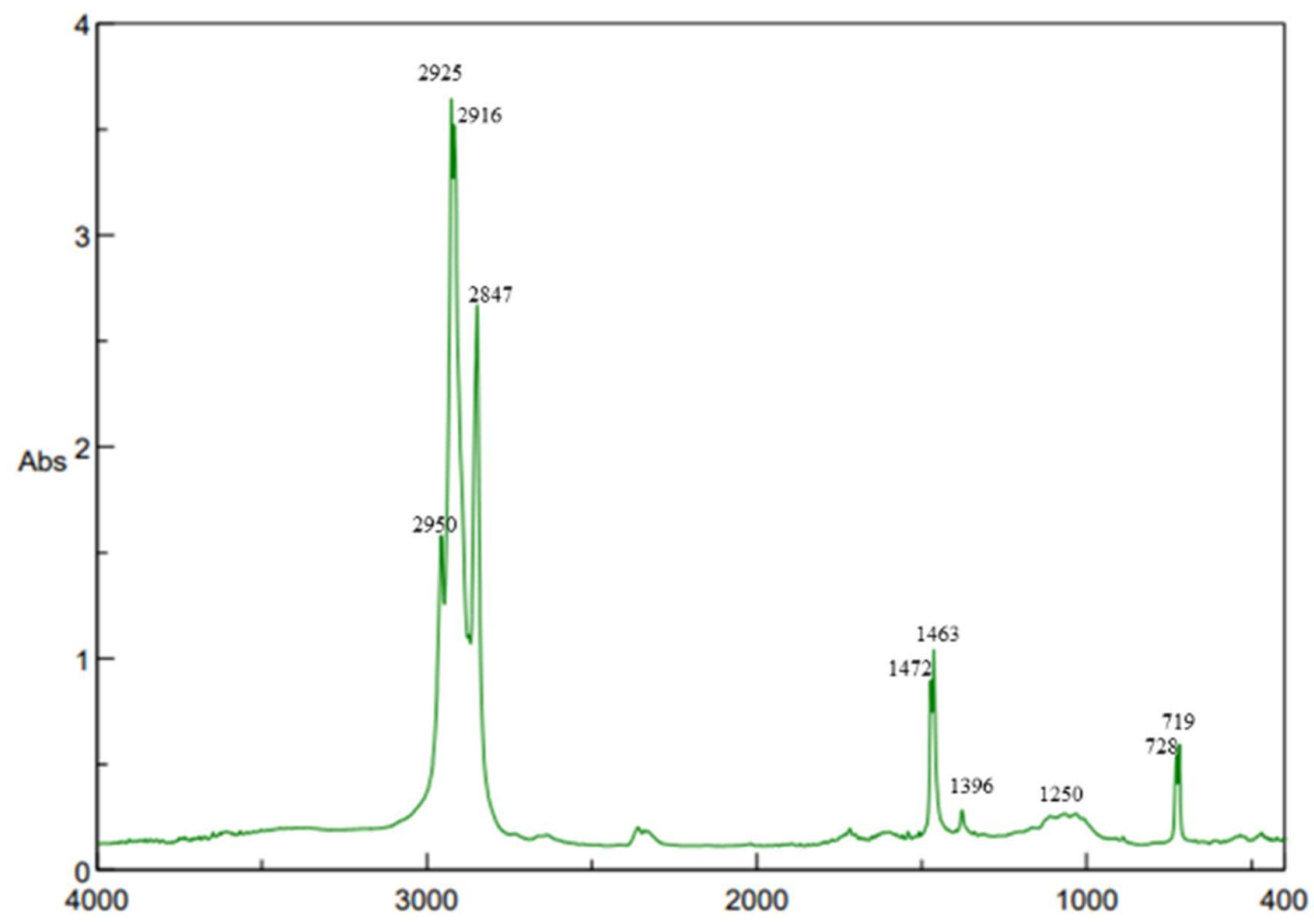

Hình 4. Phổ IR của một số loại microplastics thuộc khu vực trung tâm vịnh Tiên Yên (cm-1).

Dựa trên mức độ hấp thụ bước sóng hồng ngoại khác nhau của các liên kết hóa học, các nhóm chức của các loại Polyme sẽ có phổ (peak) khác nhau (Hình 4) [22]. Kết quả phân tích cho thấy, hạt vi nhựa trong trầm tích tầng mặt vịnh Tiên Yên có thành phần hóa học là các polyme loại Polyethylene (PE), Polypropylene (PP) Polyamide (PA), Polyvinyl chloride (PVC), Polystyrene hay PS, Polyethylene terephthalate (PET). Khu vực phía Bắc vịnh Tiên Yên có thành phần hóa học đa dạng hơn với 6 loại là $\mathrm{PE}, \mathrm{PP}, \mathrm{PA}, \mathrm{PVC}, \mathrm{PS}, \mathrm{PET}$ so với chỉ bốn loại ở vùng trung tâm là $\mathrm{PP}, \mathrm{PS}, \mathrm{PE}, \mathrm{PA}$ và 5 loại $\mathrm{PE}, \mathrm{PP}, \mathrm{PA}, \mathrm{PVC}$ và $\mathrm{PS}$ ở vùng phía Nam vịnh. Khu vực phía Bắc vịnh Tiên Yên tập trung nhiều dân cư, hoạt động đánh bắt thủy hải sản và đặc biệt là các khu công nghiệp nên nguồn rác thải nhựa từ chất thải sinh hoạt, đô thị có xu hướng phát tán hơn. Ngoài ra, khu vực này còn nằm gần thành phố Móng Cái nên có thể chịu ảnh hưởng do rác thải nhựa được vận chuyển từ khu vực này và tích tụ tại đây.

Thành phần hóa học của hạt vi nhựa trong khu vực này cho thấy nguồn gốc rác thải trong khu vực đến từ rác thải sinh hoạt, rác thải đô thị và có thể có liên quan đến hoạt động sản xuất công nghiệp dệt nhuộm tại khu vực nghiên cứu. Tuy nhiên, các loại hạt vi nhựa ở khu vực này phần lớn là loại hạt vi nhựa thứ sinh, bị vỡ ra trong quá trình phân hủy từ rác thải nhựa qua các hoạt động sinh hoạt của người dân. Nhiều nghiên cứu về sự phân bố hạt vi nhựa trong trầm tích ở môi trường tương tự trên thế giới cũng đã chỉ ra rằng nguồn gốc của các hạt vi nhựa thứ sinh tập trung chủ yếu ở gần cửa sông và các nơi tập trung đông dân cư nơi các 
hoạt động sinh hoạt của người dân diễn ra nhộn nhịp [29, 30]. Điển hình như loại nhựa PA được sử dụng làm tạo thành lưới đánh cá, bao bì nylong, vải may mặc... Nhựa $\mathrm{PE}$, là loại nhựa phổ biến sử dụng trong các loại túi nylon, thùng can, cốc nhựa, áo mưa... Nhựa PP thường sử dụng làm dây câu, bao bì, màng bọc thực phẩm, vải không dệt... Nhựa $\mathrm{PVC}$ được sử dụng phổ biến trong việc làm vải bạt, ống nước, ... [4, 5, 21]. Nhìn chung, thành phần hóa học của các loại nhựa trong môi trường trầm tích tại khu vực vịnh Tiên Yên đã phản ánh được các nguồn phát sinh rác thải nhựa từ các hoạt động nhân sinh chủ yếu trong khu vực.

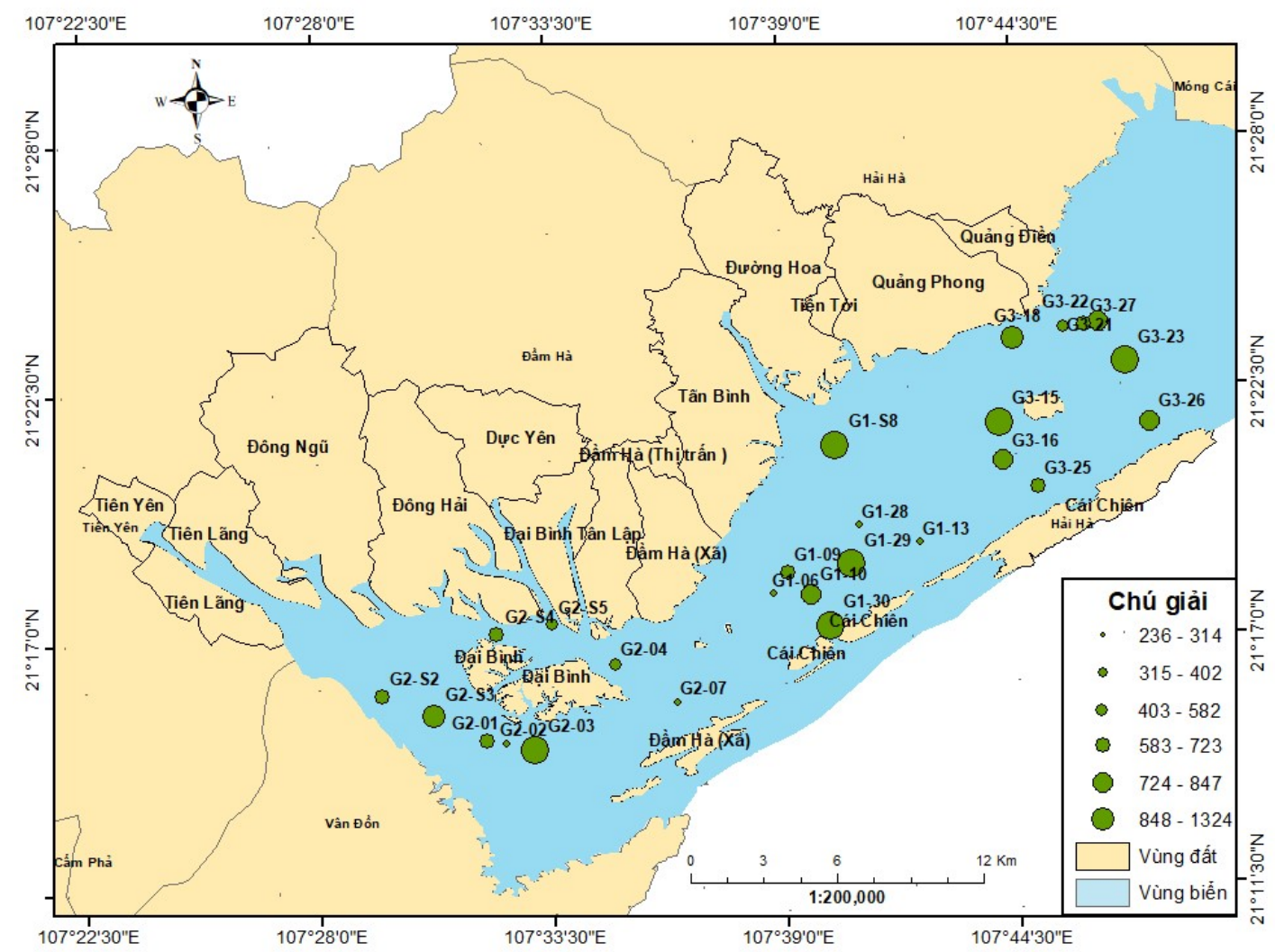

Hình 5. Bản đồ phân bố số lượng hạt vi nhựa trong trầm tích vịnh Tiên Yên.

\section{3. Đặc điểm phân bố hạt vi nhựa trong trầm tích tầng mặt vịnh Tiên Yên}

Đặc điểm phân bố thành phần số lượng hạt vi nhựa trong trầm tích tầng mặt vịnh Tiên Yên được thể hiện trong Hình 6, 7. Số lượng các hạt vi nhựa ở khu vực ven bờ thường có giá trị cao hơn khu vực giữa vịnh Tiên Yên. Khu vực phía Nam vịnh Tiên Yên với có diện tích bãi triều lớn, địa hình mở, hoạt động nhân sinh hạn chế có xu hướng tập trung số lượng hạt vi nhựa thấp hơn so với các khu vực khác. Khu vực phía Bắc vịnh Tiên Yên tập trung dân cư với nhiều hoạt động nhân sinh, khu công nghiệp, gần với thành phố Móng Cái có mức độ tập trung số lượng hạt vi nhựa trong trầm tích cao hơn các khu vực còn lại (Hình 7). Vịnh Tiên Yên là vịnh kín với tổng dòng chảy có xu hướng từ phía Bắc xuống, trao đổi nước với vùng biển bên ngoài qua chủ yếu cửa Tiểu, cửa Đại nên nguy cơ tích tụ chất ô nhiễm trong khu vực này là khá lớn [28]. Đặc điểm phân bố thành phần số lượng của hạt vi nhựa trong trầm tích tầng mặt tại khu vực vịnh Tiên Yên cho thấy số lượng hạt vi nhựa trong môi trường trầm tích có tương quan thuận với mức độ tập trung hoạt động nhân sinh. Khu vực phía Bắc tập trung nhiều hoạt động phát triển kinh tế xã hội tại thị trấn Quảng Hà, khu công nghiệp Hải Hà và gần thành phố Móng Cái có xu hướng tập trung số lượng hạt vi nhựa cao và thành phần hóa học đa dạng hơn so với vùng ven bờ huyện Đầm Hà, huyện Tiên Yên với ít hoạt động phát triển kinh tế xã hội. Kết quả này cũng phù hợp với nhiều nghiên cứu gần đây cho 
thấy rác thải sinh hoạt, đô thị và công nghiệp là nguyên nhân chính gây ra ô nhiễm rác thải nhựa trong môi trường biển và đại dương [13, 23-25, 29,30].

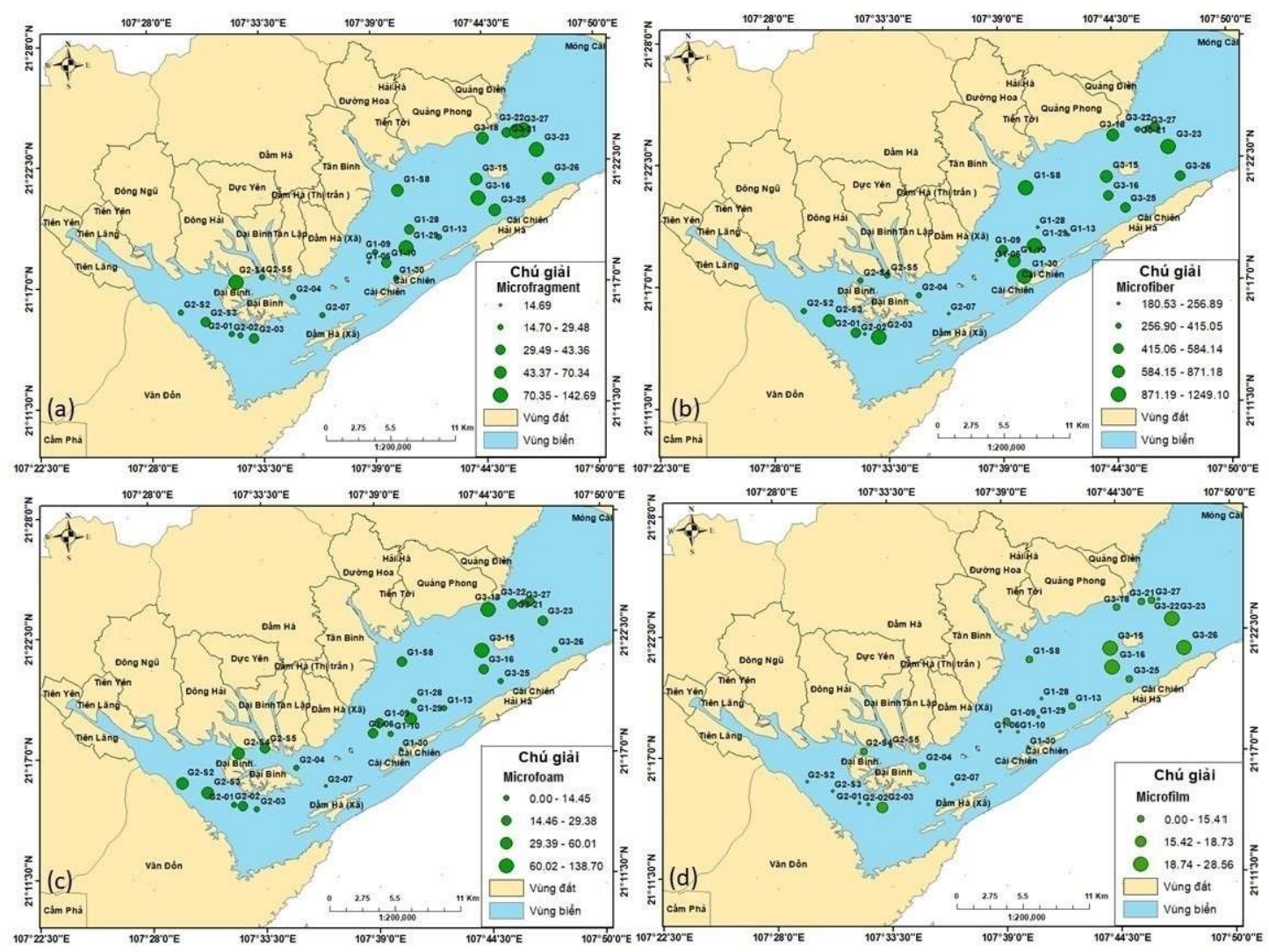

Hình 6. Phân bố các loại hạt vi nhựa trong trầm tích tầng mặt vịnh Tiên Yên.

\section{Kết luận}

Kết quả nghiên cứu cho thấy trầm tích tầng mặt vịnh Tiên Yên, tỉnh Quảng Ninh đã có dấu hiệu nhiễm bẩn các hạt vi nhựa trong môi trường trầm tích. Đặc điểm thành phần số lượng hạt vi nhựa trong môi trường trầm tích tầng mặt tại vịnh Tiên Yên ở mức tương đương với các khu vực chịu nhiều tác động của ô nhiễm rác thải nhựa trên thế giới. Thành phần hóa học của các hạt vi nhựa trong khu vực cho thấy nguồn gốc của chúng có thể liên quan đến hoạt động nhân sinh như phát triển đô thị, rác thải sinh hoạt và công nghiệp, nuôi trồng và đánh bắt thủy hải sản diễn ra trong khu vực. Tuy nhiên, để xác định chính xác nguồn phát sinh rác thải nhựa cần có các nghiên cứu chi tiết và cụ thể về quá trình vận chuyển và hành vi của các loại hạt vi nhựa tại khu vực vịnh Tiên Yên.

Đóng góp cho nghiên cứu: Xây dựng ý tưởng nghiên cứu: L.V.D., T.H.D, N.Đ.T., N.T.T.; Lựa chọn phương pháp nghiên cứu: L.V.D., T.H.D, T.Đ.Q.; Xử lý số liệu: L.V.D., T.H.D.; Phân tích mẫu: T.H.D., L.T.K.L.; Lấy mẫu: L.V.D., T.H.D, T.Đ.Q., N.Đ.T., N.T.T.; Viết bản thảo bài báo: L.V.D., T.H.D, N.Đ.T., L.T.K.L; Chỉnh sửa bài báo: T.H.D., L.V.D., N.Đ.T, T.Đ.Q., N.T.T.

Lời cảm ơn: Nghiên cứu này được thực hiện dưới sự tài trợ của đề tài nghiên cứu khoa học cấp nhà nước "Nghiên cứu xác lập bộ tiêu chí đánh giá tính bền vững vùng ven biển việt nam, thử nghiệm ứng dụng cho vùng điển hình và đề xuất giải pháp nhân rộng, Mã số: BĐKH. 23/16-20.”, mã số BĐKH.23/16-20. Tập thể tác giả trân trọng cảm ơn sự giúp đỡ của các cơ quan địa phương trong quá trình khảo sát và thực hiện nghiên cứu này. 
Lời cam đoan: Tập thể tác giả cam đoan bài báo này là công trình nghiên cứu của tập thể tác giả, chưa được công bố ở đâu, không được sao chép từ những nghiên cứu trước đây; không có sự tranh chấp lợi ích trong nhóm tác giả.

\section{Tài liệu tham khảo}

1. Thompson, R.C.; Swan, S.H.; Moore, C.J.; vom Saal, F.S. Our plastics age. Philos. Trans R. Soc. B 2009, 346, 1973-1976.

2. Henry, B.K.; Laitala, K.; Klepp, I. Microfibres from apparel and home textiles: prospects for including microplastics in environmental sustainability assessment. Sci. Total Environ. 2019, 652, 483-494. https://doi.org/10.1016/j.scitotenv.2018.10.166

3. Jambeck, J.R.; Geyer, R.; Wilcox, C.; Siegler, T.R.; Perryman, M.; Andrady, A.; Narayan, R.; Law, K.L. Plastic waste inputs from land into the ocean. Sci. 2015, 347, 768-771.

4. NOAA. Methods for the Analysis of Microplastics in the Marine Environmet Recommendations for quantifyling synthetic particles in water and sediments, in NOS-OR\&R-48. Technical Menmorandum, 2015.

5. Thompson, R.C. Plastic debris in the marine environment: consequences and solutions. Mar. Nat. Conserv. Eur. 2006, 193, 107-115.

6. Carbery, M.; O'Connor, W.; Palanisami, T. Trophic transfer of microplastics and mixed contaminants in the marine food web and implications for human health. Environ. Int. 2018, 115, 400-409.

7. Andrady, A.L. Microplastics in the marine environment. Mar. Pollut. Bull. 2011, 62, 1596-1605. https://doi.org/10.1016/j.marpolbul.2011.05.030

8. Karen Duis, A.C. Microplastics in the aquatic and terrestrial environment. Environ. Sci. Eur. 2016, 28, 2. https://doi.org/10.1186/s12302-015-0069-y.

9. Derraik, J.G. The pollution of the marine environment by plastic debris: a review. Mar. Pollut. Bull. 2002, 44, 842-852. https://doi.org/10.1016/S0025326X(02)00220-5

10. Cole, M.; Lindeque, P.; Fileman, E.; Halsband, C.; Goodhead, R.; Moger, J.; Galloway, T.S. Microplastic Ingestion by Zooplankton. Environ. Sci. Technol. 2013, 47, 6646-6655. https://doi.org/10.1021/es400663f

11. Agathe Bour, A.H.; Halland, K. Environmentally relevant microplastic exposure affects sediment-dwelling bivalves. Environ. Pollut. 2018, 236, 652-660.

12. Brennecke, D.; Duarte, B.; Paiva, F.; Caçador, I.; Canning-Clode, J. Microplastics as vector for heavy metal contamination from the marine environment. Estuarine Coastal Shelf Sci. 2016, 178, 189-195.

13. Charles, J.M. Synthetic polymers in the marine environment: a rapidly increasing,long-term threat, Synthetic polymers in the marine environment: a rapidly increasing, long-term threat. Environ. Res. 2008, 108, 131-139.

14. Gallo, F.; Fossi, C.; Weber, R.; Santillo, D.; Sousa, J.; Ingram, I.; et al. Marine litter plastics and microplastics and their toxic chemicals components: the need for urgent preventive measures. Environ Sci. Eur. 2018, 30, 13.

15. Lahens. L.; Strady, E.; Le, T.C.K.; Dris, R.; Boukerma, K.; Rinnert, E.; Gasperi, J.; Tassin, B. Macroplastics and microplastics contamination assessment of tropical river(Sai Gon river, Viet Nam) transversed by a developing megacity. Environ. Pollut. 2018, 236, 661-667. https://doi.org/10.1016/j.envpol.2018.02.005

16. Hien, T.T.; Nhon, N.T.T.; Thu, V.T.M.; Quyen, D.T.T.; Nguyen, N.T. The Distribution of Microplastics in Beach Sand in Tien Giang Province and Vung Tau City. VN J. Eng. Sci. Technol. 2020, 52, 208-221. 
17. Thạnh, T.Đ. Nguy cơ suy thoái môi trường và đa dạng sinh học vịnh Hạ Long. Tạp chí Hàng hải 2009, 53-54.

18. Thạnh, T.Đ.; Cử, N.N.A., Huy, N.H.; Nhơn, Đ.V.; Anh, Đ.H.; N.T.K. Những đặc trưng địa hệ cơ bản của vịnh Tiên Yên-Hà Cối. Tài nguyên và Môi trường biển 2008. XIII.

19. Tuấn, H.V.; T.Đ.Q.; Vượng, N.V.; Nhuận, M.T. Định hướng phân vùng chức năng sử dụng bền vững tài nguyên - môi trường vịnh Tiên Yên. Các Khoa học về Trái đất 2012, 34, 486-494.

20. Tue, N.T.; et al. Tracing carbon transfer and assimilation by invertebrates and fish across a tropical mangrove ecosystem using stable isotopes. Mar. Ecol. 2017, 38, e12460.

21. Dũng, L.V.; Dực, T.H.; Hà, N.T.H.; Tùng, N.D.; Tuệ, N.T.; Hiếu, P.V.; Định, N.Q.; Nhuận, M.T. Nghiên cứu phương pháp xác định hạt vi nhựa trong môi trường trầm tích bãi triều ven biển, áp dụng thử nghiệm tại xã Đa Lộc, huyện Hậu Lộc, tỉnh Thanh Hóa. Tạp chi Khí tuợng Thủy văn 2020, 715, 1-12.

22. Renner, G.; Schmidt, T.C.; Schram, J. Chapter 4 - Characterization and Quantification of Microplastics by Infrared Spectroscopy, in Comprehensive Analytical Chemistry. T.A.P. Rocha-Santos and A.C. Duarte, Editors 2017, 67-118.

23. Jahan, S.; Strezov, V.; Weldekidan, H.; Kumar, R.; Kan, T.; Sarkodie, S.A.; He, J.; Dastjerdi, B.; Wilson, S.P. Interrelationship of microplastic pollution in sediments and oysters in a seaport environment of the eastern coast of Australia. Sci. Total Environ. 2019, 695, 133924.

24. Tsang, Y.Y.; Mak, C.W.; Liebich, C.; Lam, S.W.; Sze, E.T.P.; Chan, K.M. Microplastic pollution in the marine waters and sediments of Hong Kong. Mar. Pollut. Bull. 2017, 115, 20-28.

25. Peng, G.; Zhu, B.; Yang, D.; Su, L.; Shi, H.; Li, D. Microplastics in sediments of the Changjiang Estuary, China. Environ. Pollut. 2017, 225, 283-290.

26. Zhang, B.; Wu, D.; Yang, X.; Teng, J.; Liu, Y.; Zhang, C.; Zhao, J.; Yin, X.; You, L.; Liu, Y.; Wang, Q. Microplastic pollution in the surface sediments collected from Sishili Bay, North Yellow Sea China. Mar. Pollut. Bull. 2019, 141, 9-15.

27. Sui, Q.; Zhang, L.; Xia, B.; Chen, B.; Sun, X.; Zhu, L.; Wang, R.; Qu, K. Spatiotemporal distribution, source identification and inventory of microplastics in surface sediments from Sanggou Bay, China. Sci. Total Environ. 2020, 723, 138064.

28. Quy, T.D.; Tue, N.T.; Nhuan, M.T. Spatial distribution of trace elements in surface sediments of Tien Yen Bay, northeast Vietnam. VN J. Earth Sci. 2012, 34, 10-17.

29. McEachern, K.; Alegria, H.; Kalagher, A.L.; Hansen, C.; Morrison, S.; Hasting, D. Microplastics in Tampa Bay, Florida: Abundance and variability in estuarine water and sediments. Mar. Pollut. Bull. 2019, 148, 97-106.

30. Li, J.; Zhang, H.; Zhang, K.; Yang, R.; Li, R.; Li, Y. Characterization, source and retention of microplastics in sandy beaches and mangrove wetlands of the Qinzhou Bay, China. Mar. Pollut. Bull. 2018, 136, 401-406. 


\section{Composition and distribution of microplastics in surface sediments of Tien Yen Bay, Quang Ninh, Vietnam}

Truong Huu Duc ${ }^{1,2}$, Luu Viet Dung ${ }^{1,2 *}$, Nguyen Dinh Thai ${ }^{2}$, Le Van Dung ${ }^{1,2}$, Le Thi Khanh Linh", ${ }^{1,2}$ Tran Dang Quy ${ }^{1,2}$, Nguyen Tai Tue ${ }^{1,2}$

${ }^{1}$ Key Laboratory of Geoenvironment and Climate Change response, University of Science, Vietnam National University, Hanoi; trhduc98@gmail.com; dungluuviet@gmail.com; levandung.qltnmtkhtn@gmail.com;lethikhanhlinh_t61@hus.edu.vn; quytrandang@gmail.com; tuenguyentai@gmail.com

2 Faculty of Geology, University of Science, Vietnam National University, Hanoi, nguyendinhthai@gmail.com

Abstract: In recent years, microplastics pollution has been strongly threatened the marine environment and marine ecosystems in the world. Previous studies showed that Vietnam is one of the leading countries in plastic wastes discharged to the ocean and microplastics pollution becomes a prior research issue in Vietnam. In the present study, we analyzed the distribution and chemical composition of microplastics in surface sediment samples from Tien Yen Bay, Vietnam. Results showed that microplastic concentrations ranged from 2361324 particles $/ \mathrm{kg}$ with the mean value was $664 \pm 68$ particles $/ \mathrm{kg}$. The composition of microplastic particles was $8.54 \%, 4.99 \%, 84.9 \%$ and $1.57 \%$ for microfragments, microfoams, microfibers, and microfilms, respectively. Chemical characteristics of microplastics showed that popular plastics such as PE, PP, PA, PVC, PS, PET were found in surface sediment samples of Tien Yen Bay. Microplastic particles were relatively concentrated in the Northern part of Tien Yen Bay and may be related to local anthropogenic activities. The level of microplastics contamination in surface sediments from Tien Yen Bay was relatively higher than other sites in the world, which required effective management measures for reducing microplastic wastes in this area.

Keywords: Microplastics; Surface sediment; Tien Yen Bay. 